\title{
Phenolic Content from Medicinal Plants and their Products Used in Veterinary Medicine
}

\author{
Erzsebet Varga ${ }^{1 *}$, Ibolya Schmidt1, Beáta Szövérfi1', Mădălina Daniela Pop¹, Hajnal Kelemen², Anita \\ Tóth ${ }^{3}$ \\ 1. University of Medicine and Pharmacy of Tîrgu Mures,Faculty of Pharmacy, Romania \\ 2. University of Medicine and Pharmacy of Tîrgu Mures, Faculty of Pharmacy, Department of Pharmaceutical Chemistry, Romania \\ 3. Semmelweis University, Department of Pharmacognosy, Budapest, Hungary
}

\begin{abstract}
Objective: The aim of the study was to determine the content of polyphenols and flavonoids from sixteen selected medicinal plants from the spontaneous Romanian flora and fifteen tinctures obtained with propylene glycol. Methods: The polyphenols were determined by the Folin-Ciocalteu method while the flavonoids by using a colorimetric method from the 10th edition of the Romanian Pharmacopoeia. The antioxidant activities of the most common nine medicinal plants and fifteen tinctures were determined by DPPH and ABTS methods. Results: The results highlighted that the phenolic compounds and flavonoids have contributed to their antioxidant activities and the medicinal plants and tinctures included in the study are rich sources of natural antioxidants. Conclusions: There are a wide variety of extraction methods for the determination of phenolics and flavonoids. The study confirms a correlation between phenolic and flavonoid contents obtained by using the DPPH and ABTS tests.
\end{abstract}

Keywords: medicinal plant, tinctures, polyphenols, flavonoids, antioxidant activities

Received 2 March 2018 / Accepted 18 June 2018

\section{Introduction}

A lot of medicinal plants from the traditional phytotherapy are used in animal healthcare. These plants are recommended in the treatment of several diseases in veterinary medicine [1]. Phenolic compounds from medicinal plants have several biological effects, such as anti-inflammatory, antioxidant properties and can play an important role in the prevention of many diseases. They also play an important role in healthcare, which are well-known in phytotherapy and ethno-veterinary practices, too $[2,3]$. The study focused on the polyphenol-rich plant products used for veterinary purposes. Studies [4] have highlighted the advantageous effects of polyphenol-rich plants and the consumption of their derived products in treating animal diseases. The present paper emphasizes the importance of these tinctures prepared from medicinal plants and their possible use, both internally as well as externally, in veterinary medicine. Tinctures used internally are extremely beneficial for the digestive and respiratory system.

Only a few studies confirm the benefits of using medicinal plants in veterinary medicine, thus by carrying out this screening our aim is to expand the area of medicinal plants and products in this field. We are interested in the most popular medicinal plants and their medicinal properties which are used in the traditional Romanian medicine.

\section{Material and methods}

Using the screening method, we determined the total phenolic and flavonoid compounds from fifteen veterinary products (tinctures) and from sixteen medicinal plants used in the preparation of these tinctures. Colorimetric and spectrophotometric methods were used to determine the content of total polyphenols and flavonoids $[5,6]$. The polyphenol concentration was determined by the FolinCiocalteu method described by Singleton and Rossi [7, 8, $9,10]$. The total flavonoid content was expressed after the official method described in the Romanian Pharmacopoeia $10^{\text {th }}$ edition with little modification [11]. In order to perform this determination methanolic, methanol and water (1:1), and ethanolic $(70 \%)$ extracts were prepared from the investigated medicinal plants. The mentioned compounds were determined directly from veterinary products in liquid form (tinctures). All the samples were measured in triplicate, and the results were expressed as mean $\pm \mathrm{SD}$ (standard deviation).

The antioxidant activity was determined by the ABTS and DPPH methods $[12,13,14]$. For these determinations methanolic, methanol and water (1:1) and water extracts were used. The antioxidant activity from nine most commonly used medicinal plants and fifteen tinctures was measured.

\section{Chemicals and instrumentation}

In order to determine the total phenolic content of the extracts, Folin-Ciocalteu phenol reagent (Scharlau, Spain), sodium carbonate (Lach-ner, Czech Republic), gallic acid (Sigma) while for the total flavonoid content aluminium 
chloride hexahydrate (Chimopar, Romania), sodium acetate (Carl Roth GmbH, Germany) and quercetin dihydrate (Extrasynthese SAS) were used. For the DPPH radical scavenging activity 1, 1-diphenyl-2-picrylhydrazyl (DPPH) and ascorbic acid were purchased from Sigma. For the ABTS radical scavenging activity 2, 2'-azino-bis (3-ethylbenzothiazoline)-6 sulfonic acid diammonium salt, potassium persulfate and Trolox were obtained from the same company. To achieve extraction, methanol (VWR Chemicals, US) and ethanol (Chemical Company, Romania) were used. Water was double distilled and purified with the Direct-Q system (Millipore, Bedford, USA). For spectrophotometric determinations a Specord 210 (Analytic Jena) was utilized.

\section{Plant material}

Several plants, such as Agrimonia eupatoria L. (herba), Arctium lappa L. (radix), Artemisia absinthium L. (herba), Betula pendula Roth (folium), Calendula officinalis L. (flos), Convolvulus arvensis L. (herba), Equisetum arvense L. (herba), Hypericum perforatum L. (herba), Lythrum salicaria L. (herba), Origanum vulgare L. (herba), Plantaginis lanceolata L. (folium), Polygonum bistorta (L.) Samp (herba), Potentilla anserina (L.) Rydb. (herba), Symphitum officinale L. (radix), Thymus serpyllum L. (herba), Urtica dioica L. (herba) were grown outside in the spontaneous flora, at Sovata, a town in Mures County. The plants were harvested in July and August 2015 and have been deposited at Sovata, a town in Mures County, Romania. Plant samples were identified in the Department of Pharmacognosy and Phytotherapy, University of Medicine and Pharmacy from Tîrgu Mures, where pieces of voucher specimen are deposited.

\section{Extracts preparation}

From the above-mentioned medicinal plants fifteen extracts were prepared using propylene glycol diluted with water $(70 \%)$ by direct pressing in a hydraulic press made by manufacturer [15]. The composition of the extracts is not available, as these are under registration and were prepared from propylene glycol and then diluted with water (70\%) since nutritional supplements can not be registered with $70^{\circ}$ ethanol.

\section{Extraction of phenolic compounds}

We prepared extracts using methanol, methanol-water (1:1) and ethanol. The herbs were crushed and $5 \mathrm{~g}$ of the sample was extracted at a temperature of $25^{\circ} \mathrm{C}$, extraction time of 30 minutes, with $50 \mathrm{ml}$ solvent in an ultrasonic bath. Extracts were filtered into a $50 \mathrm{ml}$ volumetric flask and diluted to $50 \mathrm{ml}$ with an extraction solvent.

\section{Determination of total phenolic content (TPC)}

Total phenolics were determinated by the Folin-Ciocalteu method [5]. The sample ( $40 \mu \mathrm{l}$ of extracts) was mixed with $3.16 \mathrm{ml}$ distilled water and $200 \mu \mathrm{l}$ Folin-Ciocalteu reagent; after 5 minutes, $600 \mu$ l sodium carbonate $(20 \%$ w/v) was added. The solution was left at room temperature $\left(20^{\circ} \mathrm{C}\right)$ for 2 hours. The absorbance was measured at $765 \mathrm{~nm}$ against a reagent blank (water and reagents). A calibration curve using gallic acid $\left(y=0.044 x-0.0057, r^{2}=0.9906\right)$ was used to express the phenol concentrations as $\mathrm{mg}$ gallic acid equivalents (GAE) per 100-gram dry weight or $100 \mathrm{~g}$ tincture.

\section{Determination of total flavonoid content (TFC)}

Total flavonoids from extracts were measured by the Romanian Pharmacopoeia, $10^{\text {th }}$ edition, a colorimetric, slightly modified method [11]. At the beginning, $1 \mathrm{ml}$ of the extract was mixed with $2 \mathrm{ml}$ sodium acetate $(10 \% \mathrm{w} / \mathrm{v}), 1.2$ $\mathrm{ml} \mathrm{AlCl}{ }_{3}$ solution $(2.5 \%, \mathrm{w} / \mathrm{v}), 2.8 \mathrm{ml}$ methanol and 3 $\mathrm{ml}$ water. Then, the extracts were mixed and kept at room temperature $\left(20^{\circ} \mathrm{C}\right)$ for 15 minutes before measuring the absorbance at $430 \mathrm{~nm}$. The calibration curve was prepared with quercetin $\left(y=0.156 \mathrm{x}-0.1676, \mathrm{r}^{2}=0.9954\right)$ and the results were expressed as $\mathrm{mg}$ of quercetin equivalents (QE) per 100 gram dry weight or $100 \mathrm{~g}$ tincture.

\section{DPPH radical scavenging activity}

DPPH (1,1-diphenyl-2-picrylhydrazyl) radical scavenging activity was determined by spectrophotometric in vitro decolorization assay developed by Brand-Williams [12] and was applied with some modification. $\mathrm{DPPH}^{*}$ was dissolved in HPLC grade methanol to $0.25 \mathrm{~g} / \mathrm{L}$ concentration. The stock solution was diluted with HPLC grade methanol to absorbance of $0.900 \pm 0.05$ at $515 \mathrm{~nm}$ immediately before measurement. At least 5 different volumes of the diluted sample were added to $2.5 \mathrm{~mL}$ $\mathrm{DPPH}^{\cdot}$ resulting in different final concentrations and producing inhibition of the blank solvent between $20 \%$ $80 \%$. Absorbance values were measured after $6 \mathrm{~min}$. The inhibition percentage produced by a given sample concentration was calculated from the following equation: (A0At) $/ A t^{*} 100$, where At $=$ the extrapolated final absorbance, and $\mathrm{A} 0=$ the absorbance of the blank solvent. The antioxidant activity was characterized by plotting the inhibition percentage of the samples as a function of sample concentration followed by linear regression.

\section{Determination of the antioxidant capacity by ABTS}

The ABTS (2,2'anizonbis(3-ethylbenzothiazoline-6-sulfonic acid)-diammonium salt) antioxidant activity was evaluated as described by Re [14] with slight modifications. $10 \mathrm{mg}$ ABTS radical cation (ABTS ${ }^{\bullet}$ ) was dissolved in 2.6 $\mathrm{mL}$ HPLC grade water and reacted with $1.72 \mathrm{mg}$ potassium persulfate. The $\mathrm{ABTS}^{\bullet+}$ solution was diluted with spectroscopic grade ethanol to absorbances of $0.900 \pm 0.05$ at $734 \mathrm{~nm}$. At least 5 different volumes of the diluted sample were added to $2.5 \mathrm{~mL} \mathrm{ABTS}^{{ }^{*}+}$ solution resulting in different final concentrations and producing inhibition of the blank solvent between $20 \%-80 \%$. Absorbance values were measured after $6 \mathrm{~min}$. The inhibition percentage 
produced by a given sample concentration was calculated from the following equation: $(\mathrm{A} 0-\mathrm{At}) / \mathrm{At}^{*} 100$, where $\mathrm{At}=$ the extrapolated final absorbance, and $\mathrm{A} 0=$ the absorbance of the blank solvent. The antioxidant activity was characterized by plotting the inhibition percentage of the samples as a function of sample concentration followed by linear regression.

\section{Statistical analysis}

All the experiments were carried out in triplicate, the results being expressed in mean \pm standard deviation. Statistical analysis was performed using ANOVA analysis of variance in Excel 2010. The p value $<0.05$ was considered to be statistically significant. The correlations were carried out between polyphenols and DPPH, flavonoids and DPPH, polyphenols and ABTS, flavonoids and ABTS values.

\section{Results}

The total phenolics and flavonoids were determined from sixteen medicinal plants and fifteen propylene glycol extracts. The ratio of the total phenolics and flavonoids in the extracts are presented in Table I. The polyphenol concentration values are higher than flavonoid concentrations.

The highest values of total polyphenolic concentration from the medicinal plant extracts were found from methanol and water (1:1) extracts $(5.09-48.70 \mathrm{mg}$ gallic acid/100 g dry weight) (Table I). The polyphenolic content was expressed in terms of gallic acid with values of $100 \mathrm{~g}$ of dry weight of medicinal plant. Propylene glycol extracts were also expressed in terms of gallic acid with values of $100 \mathrm{~g}$ extract. The polyphenolic values from these extracts performed on a narrow scale, these ranging between 1.58 $\mathrm{mg}$ gallic acid/100 g extract and $4.58 \mathrm{mg}$ gallic acid/100 g extract (Table I).

The highest flavonoid concentration extracted from medicinal plants was obtained with ethanolic and methanol and water extracts $(1.33-38.5 \mathrm{mg}$ quercetin equivalent/100 g dry weight from ethanolic extracts and 1.22 $-23.84 \mathrm{mg}$ quercetin equivalent/100 g dry weight plant from methanol and water extracts). The concentration of flavonoids from propylene glycol extracts ranged from $0.70 \mathrm{mg}$ quercetin equivalent $/ 100 \mathrm{~g}$ extract to $3.64 \mathrm{mg}$ quercetin equivalent/100 g extract (Table I).

The antioxidant activities of nine medicinal plants and fifteen propylene glycol extracts were estimated, as well. The radical scavenging activities with DPPH and ABTS methods are presented in Table II.

Medicinal plant extracts obtained by using methanol and water $(1: 1)$ exhibited higher values with DPPH (Agrimoniae herba: $\mathrm{IC} 50=16.9 \mu \mathrm{g} / \mathrm{ml}$, Hyperici herba: $\mathrm{IC} 50=26.3 \mu \mathrm{g} /$ $\mathrm{ml}$ ) and ABTS tests (Hyperici herba: IC50 $=0.13 \mu \mathrm{g} / \mathrm{ml}$, Calendulae flos: IC $50=0.78 \mu \mathrm{g} / \mathrm{ml}$ ), and reported notable antioxidant activity. By comparing the antioxidant activities of nine medicinal plants, investigated by using ABTS assays, the highest antioxidant activities were found in $\mathrm{Hy}$ perici herba, Calendulae flos and Agrimoniae herba.
The correlation between polyphenolics and flavonoids content obtained according to the DPPH and ABTS methods suggested that the antioxidant activities had free radical scavenging activities from medicinal plants and propylene glycol extracts, too.

Tunalier Z. et al in 2007 from Turkey performed a study regarding polyphenols expressed in gallic acid and showed similar values with one of the examined parts of the medicinal plant, Lythri herba (30-300 mg/g expressed in gallic acid). The DPPH antioxidant capacity was higher from the aqueous methanol extract followed by the methanolic extract while in our case Lythri herba showed a higher antioxidant capacity from water extract, followed by methanol and water (1:1) extract and finally by the methanolic one [16].

Artemisia absinthium from Korea (Lee et al., 2013) showed a higher concentration of flavonoid and polyphenolics from methanolic extract. Their flavonoid content showed $41 \mathrm{mg} / 100 \mathrm{~g} \mathrm{dw}$ (dry weight) flavonoid expressed in quercetin and the total phenolic content expressed in gallic acid was $131 \mathrm{mg} / 100 \mathrm{~g} \mathrm{dw}$ [17]. Our result highlighted three times less flavonoids and ten times less polyphenols than the results presented by Lee et al.

Potentilla anserina analyzed by Tomczyk et al from Poland (2010) had a flavonoid content of $4.9 \mathrm{mg} / \mathrm{g} \mathrm{dw}$ expressed in quercetin and a total phenol content of 89 $\mathrm{mg} / \mathrm{g} \mathrm{dw}$ expressed in gallic acid from water extracts [18]. Our findings are less from the ethanolic, methanolic and methanol with water extracts than the mentioned concentrations.

In case of other medicinal plants, the flavonoid and polyphenol contents were expressed in other flavonoids (rutin) or polyphenols (chlorogenic acid) and our results can not be compared with that.

Different extraction solvents influence the total polyphenol and flavonoid content as well as the antioxidant capacity. Organic solvents, like ethanol $70^{\circ}$, methanol, methanol and water can not be used directly in veterinary medicines and thus, propylene glycol is used for extracting and then obtaining the nutritional supplements used in veterinary medicine.

\section{Conclusions}

We observed a variability of phenolic and flavonoid compounds. There are a wide variety of extraction methods for the determination of phenolics and flavonoids. The study confirms a correlation between phenolic and flavonoid contents obtained by using the DPPH and ABTS tests. The methanolic:aqueous (1:1) extract of Lythri herba contains the highest concentration in polyphenols and the methanolic extract of Hyperici herba contains the most flavonoids. The aqueous extract of Origani herba is proven to have the best antioxidant effect using the DPPH methode. The aqueous extratct of Urticae herba, Hyperici herba and Origani herba have the best antioxidant effect using the ABTS method. The antioxidant values were with high antioxidant capacities of medicinal plant extracts. Polyphe- 
Table I. Flavonoid and phenolic content from parts of medicinal plants and propylene glycol extracts used in veterinary medicines

\begin{tabular}{|c|c|c|c|}
\hline Parts of medicinal plants & Solvents for extraction & Total flavonoids $\mathrm{mg} \mathrm{QE} / 100 \mathrm{~g}$ product & Total polyphenolics mg GAE/100 g product \\
\hline \multirow{3}{*}{ Bardannae radix } & ethanol $70^{\circ}$ & $11.44 \pm 2.52$ & $12.34 \pm 2.55$ \\
\hline & methanol:water (1:1) & $12.63 \pm 3.11$ & $13.25 \pm 2.71$ \\
\hline & methanol & $3.39 \pm 0.98$ & $7.59 \pm 1.49$ \\
\hline \multirow{3}{*}{ Polygonii bistortae herba } & ethanol $70^{\circ}$ & $5.08 \pm 1.11$ & $16.58 \pm 3.11$ \\
\hline & methanol:water (1:1) & $4.53 \pm 1.05$ & $13.73 \pm 2.82$ \\
\hline & methanol & $5.69 \pm 1.22$ & $10.32 \pm 1.46$ \\
\hline \multirow{3}{*}{ Betulae folium } & ethanol $70^{\circ}$ & $1.91 \pm 0.55$ & $3.63 \pm 0.61$ \\
\hline & methanol:water (1:1) & $1.34 \pm 0.31$ & $27.40 \pm 5.12$ \\
\hline & methanol & $0.25 \pm 0.11$ & $20.18 \pm 3.85$ \\
\hline \multirow{3}{*}{ Hyperici herba } & ethanol $70^{\circ}$ & $38.5 \pm 4.56$ & $44.15 \pm 7.41$ \\
\hline & methanol:water (1:1) & $23.84 \pm 3.75$ & $38.47 \pm 6.31$ \\
\hline & methanol & $33.92 \pm 5.68$ & $37.34 \pm 5.92$ \\
\hline \multirow{3}{*}{ Agrimoniae herba } & ethanol $70^{\circ}$ & $19.68 \pm 4.66$ & $40.75 \pm 6.42$ \\
\hline & methanol:water (1:1) & $18.46 \pm 3.1$ & $33.93 \pm 6.13$ \\
\hline & methanol & $6.65 \pm 2.21$ & $13.79 \pm 2.65$ \\
\hline \multirow{3}{*}{ Convolvuli herba } & ethanol $70^{\circ}$ & $7.37 \pm 2.18$ & $8.52 \pm 2.11$ \\
\hline & methanol:water (1:1) & $8.74 \pm 2.96$ & $12.71 \pm 2.32$ \\
\hline & methanol & $2.75 \pm 1.11$ & $6.29 \pm 1.73$ \\
\hline \multirow{3}{*}{ Symphyti radix } & ethanol $70^{\circ}$ & $4.08 \pm 1.96$ & $16.68 \pm 3.68$ \\
\hline & methanol:water (1:1) & $1.75 \pm 0.85$ & $5.09 \pm 1.78$ \\
\hline & methanol & $3.14 \pm 1.15$ & $3.84 \pm 1.21$ \\
\hline \multirow{3}{*}{ Lythri herba } & ethanol $70^{\circ}$ & $8.94 \pm 2.44$ & $30.52 \pm 5.62$ \\
\hline & methanol:water (1:1) & $8.64 \pm 2.51$ & $48.70 \pm 9.33$ \\
\hline & methanol & $7.07 \pm 2.06$ & $11.52 \pm 2.21$ \\
\hline \multirow{3}{*}{ Equiseti herba } & ethanol $70^{\circ}$ & $10.55 \pm 3.44$ & $18.57 \pm 2.45$ \\
\hline & methanol:water (1:1) & $12.83 \pm 3.75$ & $21.55 \pm 2.55$ \\
\hline & methanol & $4.41 \pm 0.98$ & $14.79 \pm 1.23$ \\
\hline \multirow{3}{*}{ Potentillae herba } & ethanol $70^{\circ}$ & $11.91 \pm 3.25$ & $21.55 \pm 4.52$ \\
\hline & methanol:water (1:1) & $14.15 \pm 3.96$ & $22.56 \pm 4.53$ \\
\hline & methanol & $9.52 \pm 2.85$ & $12.25 \pm 2.42$ \\
\hline \multirow{3}{*}{ Urticae folium } & ethanol $70^{\circ}$ & $13.73 \pm 3.43$ & $17.25 \pm 3.43$ \\
\hline & methanol:water (1:1) & $15.12 \pm 4.11$ & $15.21 \pm 4.43$ \\
\hline & methanol & $2.59 \pm 0.92$ & $11.69 \pm 2.23$ \\
\hline \multirow{3}{*}{ Calendulae flos } & ethanol $70^{\circ}$ & $16.17 \pm 4.22$ & $16,68 \pm 4.41$ \\
\hline & methanol:water (1:1) & $7.87 \pm 2.21$ & $16.77 \pm 4.52$ \\
\hline & methanol & $13.43 \pm 2.14$ & $14.64 \pm 3.56$ \\
\hline \multirow{3}{*}{ Absinthii herba } & ethanol $70^{\circ}$ & $11.00 \pm 1.62$ & $13.30 \pm 2.54$ \\
\hline & methanol:water (1:1) & $9.87 \pm 1.56$ & $13.41 \pm 3.31$ \\
\hline & methanol & $2.71 \pm 1.11$ & $5.38 \pm 1.74$ \\
\hline \multirow{3}{*}{ Plantaginis folium } & ethanol $70^{\circ}$ & $2.96 \pm 0.75$ & $4.16 \pm 1.82$ \\
\hline & methanol:water (1:1) & $1.22 \pm 0.52$ & $13.08 \pm 3.74$ \\
\hline & methanol & $2.20 \pm 0.48$ & $5.58 \pm 1.83$ \\
\hline \multirow{3}{*}{ Serpylli herba } & ethanol $70^{\circ}$ & $1.33 \pm 0.51$ & $10.97 \pm 2.75$ \\
\hline & methanol:water (1:1) & $2.54 \pm 0.71$ & $28.36 \pm 6.23$ \\
\hline & methanol & $1.22 \pm 0.63$ & $10.36 \pm 2.28$ \\
\hline & ethanol $70^{\circ}$ & $1.33 \pm 0.38$ & $4.98 \pm 2.11$ \\
\hline Origani herba & methanol:water (1:1) & $4.00 \pm 2.03$ & $43.41 \pm 7.96$ \\
\hline Uriganı nerba & methanol & $1.87 \pm 0.63$ & $11.70 \pm 2.22$ \\
\hline Extracts for processing & & & \\
\hline Extract number 1 & propylene glycol & $0.94 \pm 0.04$ & $2.33 \pm 0.09$ \\
\hline Extract number 2 & propylene glycol & $1.77 \pm 0.12$ & $2.37 \pm 0.09$ \\
\hline Extract number 3 & propylene glycol & $2.81 \pm 0.21$ & $4.18 \pm 0.11$ \\
\hline Extract number 4 & propylene glycol & $2.97 \pm 0.22$ & $3.06 \pm 0.12$ \\
\hline Extract number 5 & propylene glycol & $1.46 \pm 0.08$ & $2.12 \pm 0.14$ \\
\hline Extract number 6 & propylene glycol & $1.97 \pm 0.13$ & $3.96 \pm 0.98$ \\
\hline Extract number 7 & propylene glycol & $3.64 \pm 0.26$ & $4.12 \pm 0.08$ \\
\hline Extract number 8 & propylene glycol & $0.85 \pm 0.03$ & $1.64 \pm 0.09$ \\
\hline Extract number 9 & propylene glycol & $2.00 \pm 0.08$ & $3.70 \pm 1.41$ \\
\hline Extract number 10 & propylene glycol & $1.46 \pm 0.07$ & $1.58 \pm 0.49$ \\
\hline Extract number 11 & propylene glycol & $1.20 \pm 0.11$ & $3.43 \pm 0.10$ \\
\hline Extract number 12 & propylene glycol & $0.75 \pm 0.05$ & $2.59 \pm 0.29$ \\
\hline Extract number 13 & propylene glycol & $0.13 \pm 0.01$ & $1.91 \pm 0.11$ \\
\hline Extract number 14 & propylene glycol & $1.39 \pm 0.14$ & $6.15 \pm 0.13$ \\
\hline Extract number 15 & propylene glycol & $0.70 \pm 0.04$ & $4.58 \pm 0.12$ \\
\hline
\end{tabular}


Table II. Antioxidant activities of medicinal plants and propylene glycol extracts used in veterinary medicines

\begin{tabular}{|c|c|c|c|}
\hline Parts of medicinal plants & Solvents for extractions & IC $50 \%(\mu \mathrm{g} / \mathrm{mL})$ DPPH method & IC $50 \%(\mu \mathrm{g} / \mathrm{mL})$ ABTS method \\
\hline & water & 429.10 & 24.20 \\
\hline \multirow[t]{3}{*}{ Bardannae radix } & methanol:water (1:1) & 75.70 & 0.80 \\
\hline & methanol & 517.22 & 7.40 \\
\hline & water & 122.57 & 5.60 \\
\hline \multirow[t]{3}{*}{ Betulae folium } & methanol:water (1:1) & 183.90 & 3.60 \\
\hline & methanol & 45.10 & 2.60 \\
\hline & water & 37.00 & 0.01 \\
\hline \multirow[t]{3}{*}{ Hyperici herba } & methanol:water (1:1) & 26.30 & 0.13 \\
\hline & methanol & 108.45 & 27.30 \\
\hline & water & 25.00 & 4.40 \\
\hline \multirow[t]{3}{*}{ Agrimoniae herba } & methanol:water (1:1) & 16.90 & 0.01 \\
\hline & methanol & 42.56 & 8.20 \\
\hline & water & 19.20 & 1.60 \\
\hline \multirow[t]{3}{*}{ Lythri herba } & methanol:water (1:1) & 77.47 & 4.90 \\
\hline & methanol & 216.40 & 1.50 \\
\hline & water & 262.80 & 0.01 \\
\hline \multirow[t]{3}{*}{ Urticae folium } & methanol:water (1:1) & 85.11 & 0.01 \\
\hline & methanol & 124.60 & 20.00 \\
\hline & water & 446.50 & 23.00 \\
\hline \multirow[t]{3}{*}{ Calendulae flos } & methanol:water (1:1) & 224.40 & 0.78 \\
\hline & methanol & 87.55 & 25.60 \\
\hline & water & 145.00 & 18.30 \\
\hline \multirow[t]{3}{*}{ Plantaginis folium } & methanol:water (1:1) & 47.71 & 17.00 \\
\hline & methanol & 103.77 & 1.80 \\
\hline & water & 1.70 & 0.61 \\
\hline \multirow[t]{2}{*}{ Origani herba } & methanol:water (1:1) & 113.70 & 7.25 \\
\hline & methanol & 113.40 & 2.88 \\
\hline \multicolumn{4}{|l|}{ Extracts for processing } \\
\hline Extract number 1 & propylene glycol & 1.71 & 0.10 \\
\hline Extract number 2 & propylene glycol & 1.08 & 2.89 \\
\hline Extract number 3 & propylene glycol & 1.69 & 0.13 \\
\hline Extract number 4 & propylene glycol & 1.02 & 0.49 \\
\hline Extract number 5 & propylene glycol & 2.06 & 0.12 \\
\hline Extract number 6 & propylene glycol & 0.79 & 0.05 \\
\hline Extract number 7 & propylene glycol & 0.86 & 0.10 \\
\hline Extract number 8 & propylene glycol & 0.81 & 0.02 \\
\hline Extract number 9 & propylene glycol & 4.40 & 0.31 \\
\hline Extract number 10 & propylene glycol & 1.98 & 0.01 \\
\hline Extract number 11 & propylene glycol & 0.71 & 0.01 \\
\hline Extract number 12 & propylene glycol & 0.85 & 0.71 \\
\hline Extract number 13 & propylene glycol & 0.96 & 0.06 \\
\hline Extract number 14 & propylene glycol & 1.75 & 0.19 \\
\hline Extract number 15 & propylene glycol & 0.94 & 0.11 \\
\hline
\end{tabular}

nols have the potential to be integrated in these veterinary products and used to promote animal health. Our interest is to raise attention about traditional medicinal plants as potential sources for veterinary products. The phenolic compounds contributed to the antioxidant activities and the mentioned medicinal plants and extracts are a potential source of natural antioxidants.

\section{Conflict of interest}

None to declare.

\section{Acknowledgements}

The research was supported by the University of Medicine and Pharmacy of Tîrgu Mureș and SC Promedivet SRL, internal research grant number 17972/07.12.2016 and by the Erasmus Student Mobility for Placements (20162017).

\section{References}

1. Piluzza G, Viridis S, Serralutzu F et al.- Uses of plants, animal and mineral substances in Mediterranean ethno-veterinary practices for the care of 
small ruminants. Journal of Ethnopharmacology. 2015, 168: 87-99

2. Chun OK, Kim DO, Smith N, Schroeder D, Han JT, Lee ChY - Daily consumption of phenolic and total antioxidant capacity from fruit and vegetables in the American diet. Journal of the Science of Food and Agriculture. 2005, 85: 1715-1724

3. Jablonska-Rys E, Zalewska-Korona M, Kalbarczyk J - Antioxidant capacity, ascorbic acid and phenolics content in wild edible fruits. Journal of Fruit and Ornamental Plant Research. 2009, 17, 2: 115-120

4. Guimaraeas $\mathrm{R}$ et al - Characterisation of phenolic compunds in wild fruits from Northeastern Portugal. Food Chemistry. 2013, 141: 3721-3730

5. Waterhouse A.: Determination of total phenolics. in Current Protocols in Food Analytical Chemistry. R.E. Wiley, 2001

6. Balogh E.: Antioxidáns kapacitás meghatározása és ennek kialakításában szerepet játszó vegyületek vizsgálata bogyós gyümölcsök esetében. Corvinus University. PhD thesis. Budapest, 2010

7. da Silva $L A$, Pezzini BR, Soares $L$ - Spectrophotometric determination of the total flavonoid content in Ocimum basilicum L. (Lamiaceae) leaves. Pharmacognosy Magazine. 2015, 11, 41: 96-101

8. Singleton VL, Rossi JA - Colorimetry of total phenolics with phosphomolybdic-phospgotungstic acid reagents. American Journal of Enology and Viticulture. 1965, 16, 3: 144-158

9. He Z, Lan M, Lu D, Zhao H, Yuan H - Antioxidant activity of 50 traditional chinese medicinal materials varies with total phenolics. Chinese Medicine. 2013, 4: 148-152

10. Odeh I, Al-Rimawi F, Abbadi J, Obeyat L, Qabbajeh M, Hroub A - Effect of harvesting date and variety of date palm on antioxidant capacity, phenolic and flavonoid content of date palm (Phoenix dactylifera). Journal of Food and Nutrition Research. 2014, 2, 8: 499-505

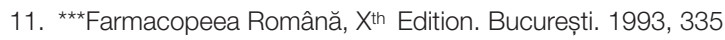

12. Brand - Williams W, Cuvelier ME, Berset C - Use of a method to evaluate antioxidant activity. Lebensm-Wiss U.-Technol. 1995, 28: 25-30

13. Emad A, Shalaby \& Sanaa M, Shanab M - Comparison of DPPH and ABTS assays for determining antioxidant potential of water and methanol extracts of Spirulina platensis. Indian Journal of Geo-Marine Sciences. 2013, 42, 5: 556-564

14. Re R, Pellegrini N, Proteggente A, Pannala A, Yang M \& Rice-Evans C - Antioxidant activity applying an improved ABTS radical cation decolorization assay. Free Radical Biology and Medicine. 1999, 26, 9-10: 1231-1237

15. CH Pearson, DJ Rath: A hydraulic press for extracting fluids from plant tissue sample. Industrial crops and products, 2009, 29: 634-637

16. Tunalier Z, Kosar M, Küpeli E, Calis I, Baser KHC: Antioxidant, antiinflammatory, anti-nociceptive activities and composition of Lythrum salicaria L. extracts, Journal of Ethopharmacology, 2007, 110: 539-547

17. Lee YI, Thiruvengadam M, Chung I-M, Nagella P: Polyphenol composition and antioxidant activity from the vegetable plant Artemisia absinthium L., Australian Journal of Crop Science, 2013, 7, 12: 1921-1926

18. Tomczyk M, Pleszczyńska M, Wiater A: Variation in total polyphenolics contents of aerial parts of Potentilla species and their anticariogenic activity, Molecules, 2010, 15: 4639-4651 